\title{
Recombination and Metastability in Amorphous Sillicon and Silicon Germanium Alloys
}

\section{Annual Subcontract Report 1 February 1991 - 31 January 1992}

M. Silver

University of North Carolina

Chapel Hill, North Carolina

NREL technical monitor: B. von Roedern

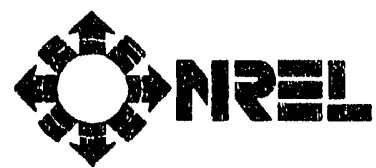

National Renewable Energy Laboratory 1617 Cole Boulevard Golden, Colorado 80401-3393

A Division of Midwest Research Institute Operated for the U.S. Department of Energy under Contract No. DE-ACO2-83CH10093

Prepared under Subcontract No. XG-1-10063-5

July 1992

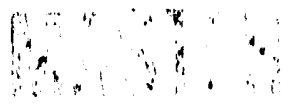


This publication was reproduced from the best available camera-ready copy submitted by the subcontractor and received no editorial review at NREL.

\title{
On September 16, 1991 the Solar Energy Institute was designated a national laboratory, and its name was changed to the National Renewable Energy Laboratory.
}

\section{NOTICE}

This report was prepared as an account of work sponsored by an agency of the United States government. Neither the United Stales government nor any agency thereof, nor any of their employees, makes any warranty, express or implied, or assumes any legal liability or responsibility for the accuracy, completeness, or usefulness of any iniormation, apparatus, product, or process disclosed, or represents that its use would not infringe privately owned rights. Reference herein to any specific commercial preduct, process, or senvice by trade name, trademark, manufacturer, or otherwise does not necessarily constitute or imply its endorsement, recommendation, or favoring by the United States goverriment or any agency thereof. The views and opinions of authors expressed herein do not necessarily state or reflect those of the United States government or any agency thereof.

\author{
Printed in the United States of America \\ Avallable from: \\ National Technical information Service \\ U.S. Department of Commerce \\ 5285 Port Royal Road \\ Springfield, VA 22161
}

Price: Microfiche AO1

Printed Copy AOB

Codes are used for pricing all publications. The code is determined by the number of pages in the publication. Information pertaining to the pricing codes can be found in the current issue of the following publications which are generally available in most libraries: Energy Research Abstracts (ERA);

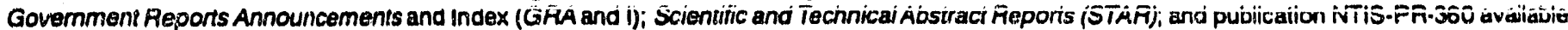
from NTIS at the above address. 


\section{PREFACE}

This report covers the first year of a continuing research study to understand how recombination, trapping and band-mobility modification affecting the electronic properties of amorphous semiconductors can be measured, characterized and described by an appropriate spectrum of defect states and how light-induced defects in a-Si:H and native defects in a-SiGe:H affect transport properties in these materials.

It is well known that light-induced effects (SWE) increase the density of states near the dark. Fermi-level. There is a concomitant increase in the spin density probably due to an increase in the dangling bond density. The question that arises is can one relate the dectcase in carrier lifetime directly to the measured increase in the density of deep states? To answer this we study experimentally and theoretically electroluminescence, recombination, electronic transport and photocarrier generation in a-Si:H and a-SiGe:H alloys. The information gleaned will certainly be relevant to the Staebler-Wmnski effect.

The work at Chapel Hill is performed by:

Professor Marvin Silver

Daxing Han - Research Associate

Keda Wang - Research Associate

Mathieu Kemp - graduate student 


\section{SUMMARY}

Our objectives were to determine how the Staebler-Wronski defects affect the electronic processes in a-Si:H and a-SiGe:H films. In order to attain these objectives, we studied both experimentally and theoretically electroluminescence and forward bias currents in $p-i-n$ devices ( $i$-layer thickness $>2 \mu \mathrm{m}$ ) before and after light soaking. We developed a simple picture to compare forward bias current to the EL signal. Contrary to previous misconceptions, the EL efficiency is high (as high as PL). Because the EL efficiency is $\eta=$ $E L / j_{r}$, where $j_{r}$ is the recombination part of the current and not $E L / j F$ where $j_{F}$ is the total current. The substantial difference between $E L / j_{r}$ and $E L / j F$ is that under forward bias there is gain factor $G=j F / j_{r}$, consequently $\eta=(E L / j F) \times G$.

With the gracious hospitality of Reinhard Carius at Julich, we were able to show that the total emission of EL collected by a IR-photomultiplyer is consistent with the main band emission, the later data taken with a Ge detector at Julich.

Transient forward bias measurements of $p-i-n$ junctions before and after light soaking occupied the majority of our experimental energy. We obtained the unexpected results that the product of the final current times the rise time was not constant before and after light soaking as expected from the concept of gain band width but changed radically. The rise time $t_{r}$ increased by more than one order of magnitude while the final current $I_{f}$ did not change significantly with light soaking. On the other hand, the $\mathrm{I}_{\mathrm{ft}}$ product did hold close to a constant when only the applied voltage changed.

Theoretically, we made significant progress on a microscopic model for radiative, recombination. Including the coulomb interaction, there are two major contributions to the time dependence of the luminescence: 1) nearest neighbor tunneling between the hole and electron and 2) a transport controlled process where the rate limiting step is a long distance hop between electrons in tail states. These calculations are able to reproduce the frequency spectra of low temperature luminescence and also the dependence upon excitation intensity. 
Our research last year has resulted in 11 papers being submitted for publication. 


\section{Table of Contents}

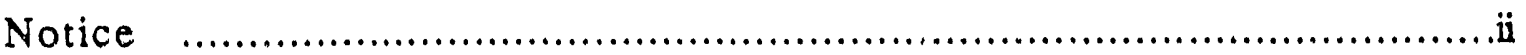

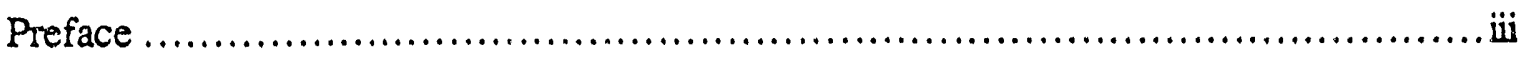

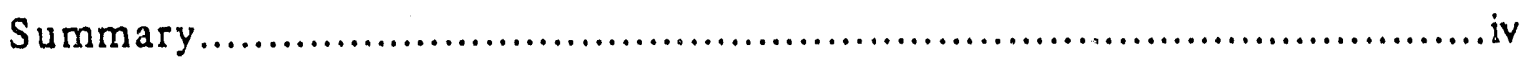

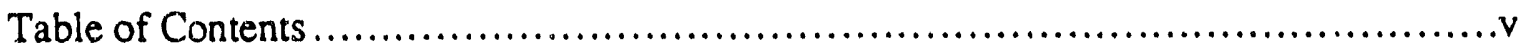

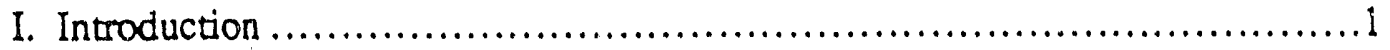

II. Results..........................................................

A) Experimental Results.............................................2

1) Forward Bias Current .............................................2

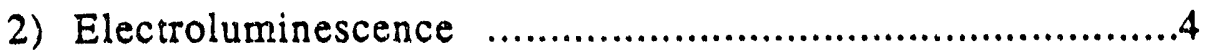

3) Model ....................................................6

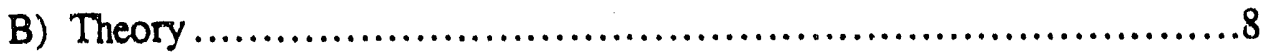

C) Publications .................................................. 11

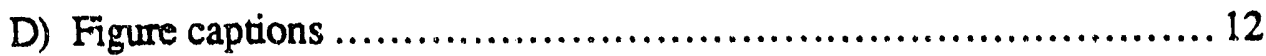




\section{Introduction}

Prolonged illumination of silicon-hydrogen based solar cells clearly lowers the efficiency. It is well known that the prolonged illumination increases the density of dangling bonds and possibly other defects which decreases the recombination lifetime of photogenerated carriers. There are two major problems: 1) what is the mechanism and kinetics of the formation of these photogenerated recombination centers and 2) what are the factors governing the recombination itself.

In our research, we have chosen to attempt to understand the recombination. Through this understanding, remedial procedures may be suggested. The radiative- and non-radiative- recombination can determine the electroluminescence and the forward bias current in p-i-n devices. The results reported below came from our first year's activity under this sub-contract. 


\section{Results}

A) Experimental Results

1) Forward Bias Current

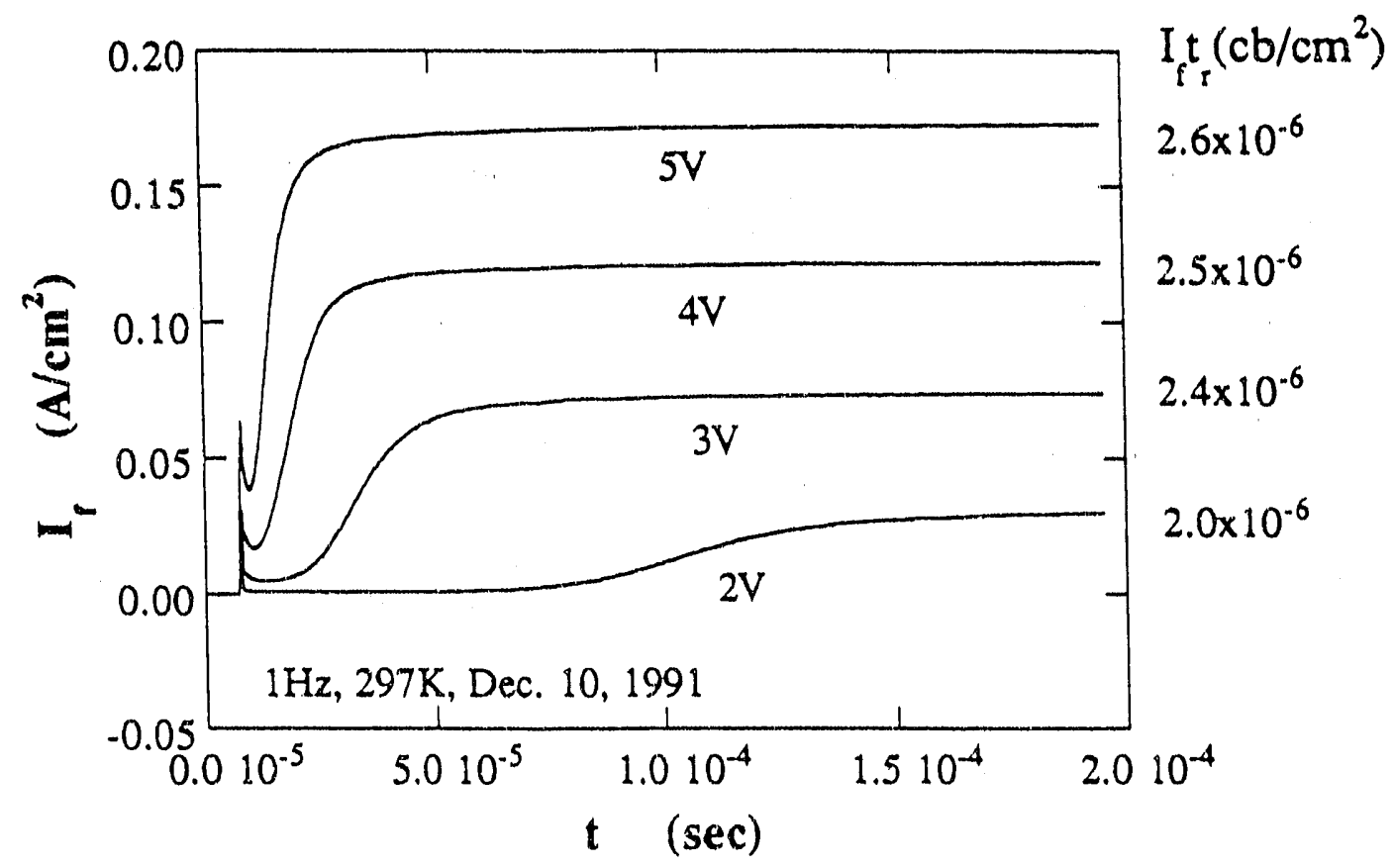

Fig. 1 Applied voltage dependence of Forward current in a $2 \mu \mathrm{m} \mathrm{p}$ - $\mathrm{i}-\mathrm{n}$ diode at state $\mathrm{A}$.

Fig. 1 shows the applied voltage dependence of forward bias current in a $2 \mu \mathrm{m} p-i-n$ diode. The response-time $t_{r}$ is approximated by the extrapolated time to reach the final value for the current $I_{f}$ and the product of $I_{f} t_{r}$ is given on each curve along with the magnitude of the applied voltage. We found that the product of $I_{f_{r}}$ is approximately constant for transient forward biased currents vs voltage in a-Si:H diodes ( the same rule was found in compensated material previously ${ }^{1}$ ). The product of $\mathrm{Ift}_{\mathrm{ft}}$ is somewhat equivalent to a gainbandwidth jroduct ${ }^{2}$. It will be discussed in part $B$.

Although the current vs time is depicted only to $2 \times 10^{-4} \mathrm{~s}$, our data shows the current to be constant (after the rise) up to $5 \times 10^{-2}$, the limit of our pulse generator. 
Further, an examination of $\tau_{\tau}$ shows that it is not related to the transit time of holes because if it were $\tau_{\Upsilon} \propto 1 / \mathrm{V}$ and the data shows that it is more nearly $\propto 1 / V^{2}$.

We have also studied how I $\mathrm{ft}_{\mathrm{r}}$ product varies with photodegradation. These results are shown in figures $2 \mathrm{a}$ and $2 \mathrm{~b}$ for a $2 \mu \mathrm{m}$ and $10 \mu \mathrm{m} \mathrm{p}-\mathrm{i}-\mathrm{n}$ diodes, respectively. Notice, there was a negative bias instead of zero bias between the positive pulses. State $\mathbf{A}$ is annealed state and state B1-B5 is step by step light-soaked states for the same dot. As one can see, for the same voltage $t_{r}$ increases significantly after photodegradation. What is curious is that the inagnitude of the forward bias current $I_{f}$ does not change much but only the response time $t_{r}$ inisteases significantly. We will continue to study this phenomena during the next year.

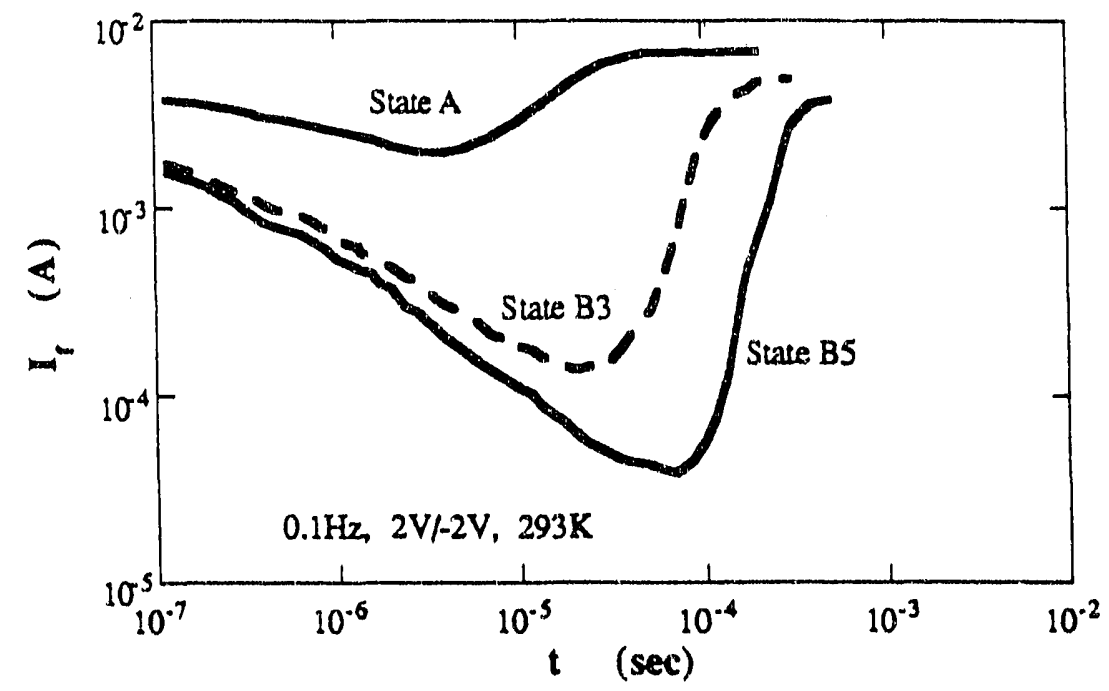

Fig. 2a The forward current as a function of light-soaking for a $2 \mu \mathrm{m} \mathrm{p}-\mathrm{i}-\mathrm{n}$ diode. The forward bias pulse repetition rate was $0.1 \mathrm{~Hz}$ and the amplitude of the positive pulse is $2 \mathrm{~V}$ with a negative bias $-2 \mathrm{~V}$ between positive pulses. 


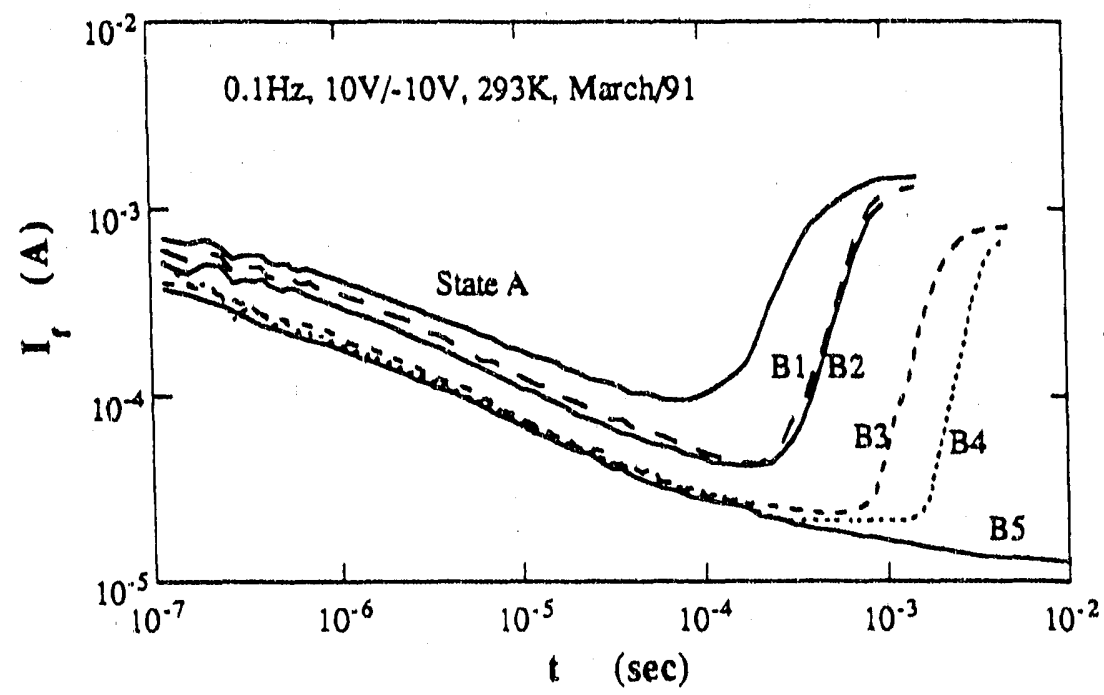

Fig. $2 b$ The forward current as a function of light-soaking for a $10 \mu \mathrm{m} p-i-n$ diode.

2) Electroluminescence

Last year we showed ${ }^{3}$ that, in the temperature range of $80<\mathrm{T}<300$ under constant voltage condition, the EL/jF vs. T gives a straight line with a slope about $30 \mathrm{~K}$ which shows a constant radiative-lifetime $\tau_{L}$. This means that any change in El or forward bias current with temperature is attributable to the change of the non-radiative-lifetime $\tau$. This year, EL. was studied in both our lab and KFA, Julich for our $p-i-n$ devices. In our lab the EL data were collected by a IR-photomultiplyer with an cut-off energy $1.1 \mathrm{eV}$; in KFA the data were collected by a Ge-detector with an cut-off energy $0.75 \mathrm{eV}$. In particular, we studied the comparison of the total emission with the emission spectra. Concerning the main band amission, the EL/jF vs. T measured in KFA gives a straight line with a slope of $34 \mathrm{~K}$ which is consistent with the previous results ${ }^{3}$. We found that as temperature decreases from $250 \mathrm{~K}$ to $60 \mathrm{~K}$ the main band peak energy shifts only by about $0.1 \mathrm{ev}(1.1 \mathrm{ev}$ to $1.2 \mathrm{ev})$. These results are shown solid lines in figure 3 for a $2 \mu \mathrm{m} p-i-n$ at $250 \mathrm{~K}$ and $60 \mathrm{~K}$. We were not able to make measurements below $60 \mathrm{~K}$ for "thick" samples. However, Dr. Carius ${ }^{4}$ did 
measure EL on $0.5 \mu \mathrm{m}$ samples at $30 \mathrm{~K}$ and below. These results are also shown in figure 3 as doted lines. Interestingly, the peak energy for EL at $30 \mathrm{~K}$ is shifted only $0.05 \mathrm{ev}$ from those found in our thick samples at $60 \mathrm{~K}$. However, the $250 \mathrm{~K}$ results are quite different. For the thin samples, the peak energy is $0.95 \mathrm{ev}$ while in thick samples it is $1.1 \mathrm{ev}$. It is cleax that the shift in the peak energy at high temperatures is much greater in the thin samples than in thick one. This effect must be studied further.

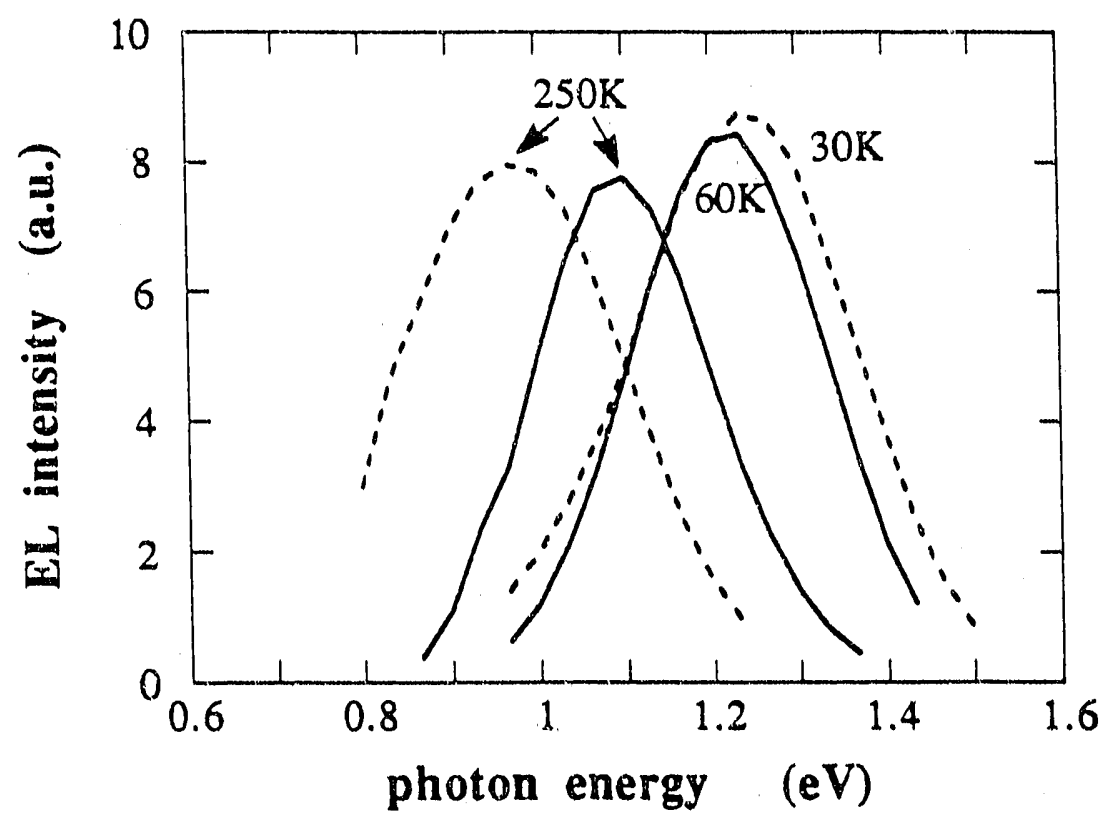

Fig. 3 EL spectra temperamure dependence. The solid and doted lines are corresponding to $2 \mu \mathrm{m}$ and $0.5 \mu \mathrm{m} \mathrm{p}-\mathrm{i}-\mathrm{n}$ diodes, respectively.

We have obtained the transient response of EL in our thick samples. The response is due to the "turn-off" of the forward bias pulse in the p-i-n structures. This data is shown in figure 4 where we plot $\ln (E L \times t)$ vs $\ln t$. Plotting the data this way is equivalent to obtaining the radiative lifetime spectra ${ }^{5}$ Notice that there are two peaks; one at approximately $10^{-6} \mathrm{sec}$ and the other at $10^{-4} \mathrm{sec}$. This structure is similar to that reported for photoluminescence by Ambros et al.5 The similarity between EL. and PLo indicates 
that the generation mechanism is not important but that the lifetimes are governed primarily by the recombination process itself.

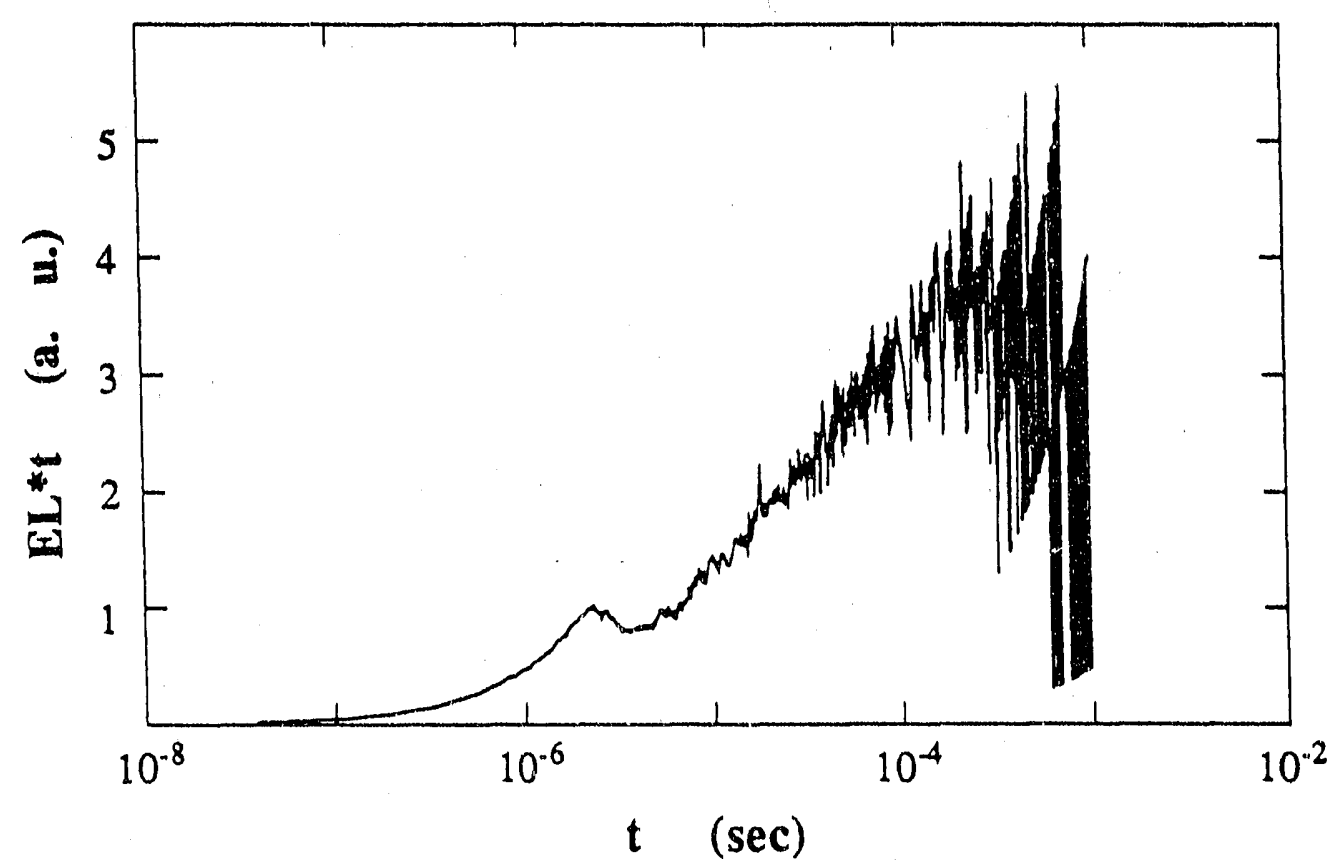

Fig. 4 The recombination lifetime distribution obtained from EL decay.

3) Model

During the past year we established a phenomenological model for double injection. Since EL represents some fraction of the recombination current, this simple model can be applied to it as well. Figure 5 schematically represents the current flow. To evaluate the recombination current the current flow in the circuit can be written as

(1) $\quad \nabla \cdot j=g-\nabla \cdot j_{r}$

where $\mathrm{j}_{\mathrm{r}}$ is the recombination current and $\mathrm{g}$ is the effective generation rate. Integrating over the entire volume of the diode one has

(2) $\quad I_{\text {out }}-I_{\text {in }}=\frac{C V}{t_{\text {om }}}-I_{x}$ 
where $\mathrm{CV} / \mathrm{t}_{\mathrm{o}}$ is the injected current from the contacts in which $\mathrm{C}$ is the genmetric capacitance of the diode and tom is the mutual average transit time of the carriers. Mark and Lampert 6 approximate the mutual average transit time using the ambipolar mobility of the two carriers. In the case of a-Si:H with the complicated density of localized states, the ambipolar concept may be a little naive and so rather than define tom we leave it in general terms. for this qualitative picture, lumping them together should give an adequate physical picture. Now from Eq. (2), since both $I_{\text {in }}$ and $L_{\text {out }}$ sinust equal to the circuit current $I_{f n}+$ $I_{\text {fp }}$, one has $I_{r}=C V / t_{0 m}$ in steady state. The meaning of this is that the recombination current adjusts itself through the population of recombination centers so that $\mathrm{CV} / \mathrm{tom}_{\mathrm{om}}=\mathrm{I}_{\mathrm{r}}$ at steady state.

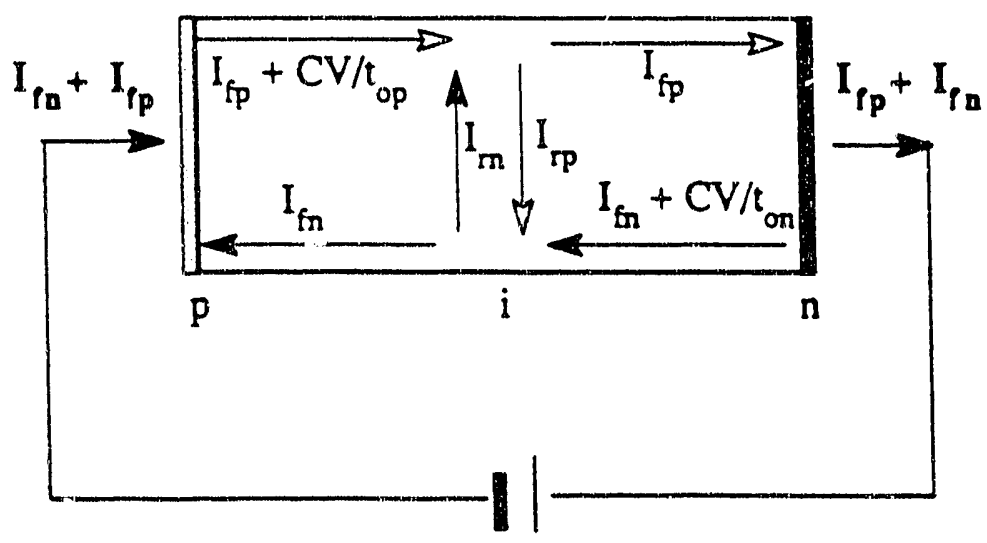

Fig. 5a Schematic plot of the electrons and holes flow through a p-i-n diode.

Fig. 5a is a schematic plot of the current flow through a p-i-n diode. Computer simulations are needed for solving a complete set of kinetic equations for the holes and electrons; however, to give a semi-quantitative picture we use the equivalent diagram shown in figure 5b. Both the hole and electron injection currents are contained in the term $\mathrm{CV} / \mathrm{tom}$. 


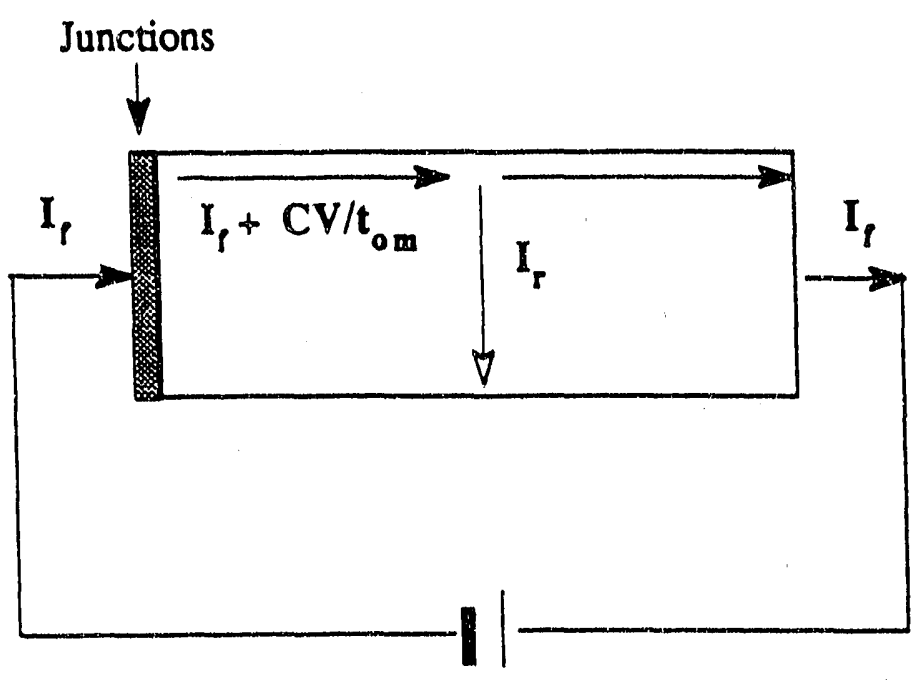

Fig. 5b Simplified plot of the current flow through a p-i-n diode by using a mutual average transit time $t_{\text {om }}$.

$$
I_{f}=\frac{C V}{t_{0}} G=I_{r} \frac{\tau}{t_{0}}
$$

We have argued ${ }^{3}$ that one should not use $\eta *=E L / I_{\mathrm{f}}$ as the EL efficiency, but $\eta=E L / I_{\mathrm{r}}=$ $\eta *\left(\tau / t_{0}\right)$. It should also be remarked, that the radiative-lifetime $\tau_{L}$ is larger than the nonradiative-lifetime $\tau$, the EL efficiency, therefore is $\eta=\eta *\left(\tau L t_{0}\right)$, which is comparable with that of PL.

\section{B. Theory}

Our theoretical research has focused on two problems: 1) an explanation for the shape of the forward bias current in a p-i-n structure as a function of photodegradation and 2) the time dependence of recombination as evidenced by the frequency dependence of the luminescence. We have only just started on the former problem and have made significant progress on the latter. 
In figure 2, we see that photodegradation does not affect the final current as much as it prolongs the rise of the forward bias current. At present we can only speculate that this strange result comes about because the recombination in steady state is controlled by different states (perhaps band tails) than the transient which surely is controlled by the density and capture rate of deep defect centers since these must be filled in order for the quasi fermi level to rise. We have noticed that the data in Fig.2 were taken with a negative bias, because there was accumulated charges near the junction without negative bias.

We plan to try to calculate these results more carefully but at present we only have a naive phenomenological inodel. What figure 2 shows is that the product $I_{\mathrm{f}} \mathrm{t}_{\mathrm{r}}$ increases with photodegradation. The quandity $\mathrm{I}_{\mathrm{f}} \mathrm{t}_{\mathrm{r}}$ can be estimated from the following phenomenological argument. From Eq. (3) and the relation of $t_{r}=\tau\left(1+n_{v} / n\right) \approx \tau\left(n_{v} / n\right)$ (where $n_{t}$ and $n$ are the density of trapped and free carries, respectively), one has

$$
I_{\mathrm{f}} \tau_{\mathrm{T}}=\frac{C V}{t_{0}} \tau \tau \tau \frac{n_{t}}{t_{0}}
$$

Now since $\tau=\left(N_{r} b\right)^{-1}$, by assuming the density of the recombination centers $N_{r}$ is approximately the same as the injected charge concentration, one can write

$$
\begin{aligned}
& \text { (5) } \tau=\frac{1}{b \frac{C V}{e L} \frac{\tau}{t_{0}}} \\
& \text { and } \tau^{2}=\frac{e L t_{0}}{b C V} \text {, }
\end{aligned}
$$

so finally by inserting $\mathrm{Eq}(5)$ into $\mathrm{Eq}$. (4) one has

$$
\text { (6) } \quad I_{f} t_{r}=\frac{e l}{b t_{0}} \frac{n_{t}}{n} \text {. }
$$

The gain-bandwidth product is $G \Delta B=\left(\tau / t_{0}\right)(1 / \tau)=1 / t_{0}$, and when $V C \geq e n L$, $t_{0}$ is equal to the dielectric relaxation time, $\tau_{\text {rel }}=(x / 4 \pi \sigma) 10^{-12}$. So that the $I_{f_{1}}$ product in Eq.(6) is somewhat like the gain-bandwidd? product ${ }^{2}$ in photoconductors. If $I_{f t r}$ is to increase upon 
photodegradation either $b$ or $t_{0}$ must decrease, or $n / n$ increase. It is not likely that $t_{0}$ decreases because this would imply an increase in band mobility contrary to recent experiments ${ }^{7}$. Consequently, either $n / n$ increases or the recombination rate constant $b$, for photogenerated defects is smaller than those for thermal defects. This also requires further study.

Now, the above phenomenological model requires substantiation before it can be accepted. We plan to take more data for different samples at varying temperatures and attempt microscopic modelling for these processes during the coming year. Nevertheless, it seums plausible to suppose that photogenerated defects are formed in regions of high strain or local potential energy and therefore might have a small recombination rate constant because of the barriers still present after formation of the defect.

We have now succeeded in putting forth a microscopic model for low temperature luminescence and therefore recombination (see our SERI annual report 1990-91). What we have done is to include the effects of the coulomb interaction and the magnitude of the localization radius on the low temperature luminescence. For small energetic disorder, the coulomb interaction produces anisotropic recombination dynamics while for large disorder, the recombination remains isotropic A small $\left(<10^{-7} \mathrm{~cm}\right)$ localization radius leads to a transport controlled recombination where the lifetime is governed by the longest jump between tail states rather than the final radiative jump between the electron and hole. Using these ideas we calculate the frequency dependence of the luminescence, show that there are two peaks, as a function of excitation density. As a consequence, we show how the fraction of geminate pair recombination varies with excitation density.

For the moment, we use monte-carlo methods for our calculations. Rather than repeat the details of the calculations, we attach a preprint of a letter ${ }^{7}$ to the editor to Phil. Mag. B. For the future, we will extend our calculations to higher temperanre and also seek analytic solutions to the problem including the coulomb interaction. 


\section{References:}

1. G. Winborne, Le Xu and M. Silver, MRS Proc. 118 (1988) 501.

2. A. Rose, "Concepts in Photoconductivity and Allied Problems", ( Robert E. Krieger Publishing Co., Huntington, New York, 1978), chapter 2.

3. K. Wang, D. Han and M. Silver, "Amorphous Silicon Materials and Solar Cells." AIP Conference Proc. 234, ed. by Byron L. Stafford, (New York, 1991 ), 162; K. Wang, D. Han, M. Silver and H. Branz, Solar Cells, 30, (1991), 219; K. Wang, D. Han, M. Kemp and M. Silver, J. Non-Cryst. Sol.137/138 (1991) 599.

4. R. Carius, MRS Proc.Vol.192, "Amorphous Silicon Technology-1990" p.101.

5. S. Ambros, R. Carius and H. Wagner, 14th Intemational Conference on Amorphous Semiconductors, Aug. 19-23, 1991, Garmisch, Germany, to be published in J. NonCryst. Sol. (1991).

6. M. Lampert and P. Mark, "Current injection in solids" (Academic Press, N.Y.) 1970.

7. Private communication with Bolko Von Roedem.

8 "Transport controlled recombination", M. Kemp and M. Silver, to be published by Phil. Mag. Lett. 


\section{Publications}

\section{Published:}

1. "Comment on Theoretical Investigation of Transient Space-charge-limited Currents for Dispersive Transport in Amorphous Silicon", M. Silver, Daxing Han, Keda Wang and M. Kemp, Phil. Mag. Letts. 64 (1991) 379.

2. "Origin of the Low-temperature Drift Mobility Increase in a-Si:H", M. Kemp and M. Silver, Phil. Mag B63 (1991) 437.

3. "Influence of the Coulomb Potential on Photoluminescence", an invited talk in the 4th international conference on hopping and related phenomena, M. Kermp, D. Han and M. Silver, (Marburg, Germany, Aug 26-29, 1991).

4. "What Electroluminescence and Transient Space Charge Limited Currents Tell Us about Steabler-Wronski Effects", K. Wang, D. Han and M. Silver, Amorphous Silicon Materials and Solar Cells." AIP Conference Proc. 234, ed. by Byron L. Stafford, ( New York, 1991 ), 162.

5. "Metastability in Hydrogenated Amorphous Silicon: the Adler Model Revised", H. M. Branz, R. S. Crandall and M. Silver, AIP Conf. Proc. 234, Amorphous silicon materials and solar cells, (AIP, New York, 1991) 29.

6. "Electroluminescence Studies of Recombination in Hydrogenated Amorphous Silicon p-i-n Devices", K. Wang, D. Han, M. Silver and H. Branz, Solar Cells, 30, (1991), 219.

7. "Temperature and Current Dependence of Electroluminescence in a-Si:H", Keda. Wang, Daxing. Han, M. E. Zvanut and M. Silver, Phil. Mag. B63, (1991) 175.

8. "Electroluminescence: a Study of Non-geminate Radiative and Non-radiative Bulk Recombination", K. Wang, D. Han, M. Kemp and M. Silver, J. Non-Cryst. Sol. $137 / 138$ (1991) 599.

9. "Light Induced Metastable Defects in a-Si:H Studied by Transient Space Charge Perturbed Currents", Daxing. Han, Keda. Wang and M. Silver, J. Non-Cryst. Sol. 137/138 (1991) 267.

\section{To be published:}

10. "The puzzle surrounding luminescence models", M. Kemp and M. Silver, to be published in J. Non-Cryst. Sol (1992)

11. "Transport controlled recombination", M. Kemp and M. Silver, submitted to Phil. Mag. Lett. 


\section{Figure captions}

Fig. 1 Applied voltage dependence of forward current in a $2 \mu \mathrm{m}$ p-i-n diode at state A.

Fig. 2 a) The transient forward current as a function of light-soaking for a $2 \mu \mathrm{m}$ p-i-n;

b) The transient forward current as a function of light-soaking for a $10 \mu \mathrm{m} p-i-n$.

Fig. 3 EL spectra temperature dependence. The solid and the doted lines are corresponding to $2 \mu \mathrm{m}$ and $0.5 \mu \mathrm{m} \mathrm{p}-\mathrm{i}-\mathrm{n}$ diodes, respectively.

Fig. 4 The recombination lifetime distribution obtained from EL decay.

Fig. 5 a) Schematic plot of the electrons and holes flow through a p-i-n diode.

b) Simplified plot of the current flow through a p-i-n diode by using a mutual average transit time tom for both electrons and holes. 


\begin{tabular}{|c|c|c|c|}
\hline $\begin{array}{c}\text { Document Control } \\
\text { Page }\end{array}$ & $\begin{array}{l}\text { 1. NREL Roport No. } \\
\text { NREL/TP-451-4962. }\end{array}$ & $\begin{array}{l}\text { 2. NTIS Accession No. } \\
\text { DE92010593 }\end{array}$ & 3. Reciplent's Accession No. \\
\hline \multirow{2}{*}{\multicolumn{3}{|c|}{$\begin{array}{l}\text { 4. Title and Subtitle } \\
\text { Recombination and Metastability in Amorphous Sulicon and Silicon Germanium } \\
\text { Alloys }\end{array}$}} & $\begin{array}{l}\text { 5. Publloation Dato } \\
\text { July } 1992 \\
\end{array}$ \\
\hline & & & 6. \\
\hline \multicolumn{3}{|l|}{$\begin{array}{r}\text { 7. Author(s) } \\
\text { M. Silver }\end{array}$} & 8. Performing Organization Rept. No. \\
\hline \multirow{2}{*}{\multicolumn{3}{|c|}{$\begin{array}{l}\text { 9. Performing Organlzatlon Name and Address } \\
\text { University of North Carolina } \\
\text { Chapel Hill, Norih Carolina 27599-3255 }\end{array}$}} & $\begin{array}{l}\text { 10. Project/TaskWork Unit No. } \\
\text { PV241101 }\end{array}$ \\
\hline & & & $\begin{array}{l}\text { 11. Coniract (C) or Grant (G) No. } \\
\text { (C) XG-1-10063-5 } \\
\text { (G) }\end{array}$ \\
\hline \multirow{2}{*}{\multicolumn{3}{|c|}{$\begin{array}{l}\text { 12. Sponsoring Organizatlon Name and Address } \\
\text { National Renewable Energy Laboratory } \\
1617 \text { Cole Blvd. } \\
\text { Golden, CO } 80401-3393\end{array}$}} & $\begin{array}{l}\text { 13. Type of Report \& Perlod Coverad } \\
\text { Technical Report } \\
\text { 1 February } 1991 \text { - } 31 \text { January } 1992\end{array}$ \\
\hline & & & 14. \\
\hline \multicolumn{4}{|c|}{$\begin{array}{l}\text { 15. Supplementary Notes } \\
\text { NREL technical monitor: B. von Roedern }\end{array}$} \\
\hline \multicolumn{4}{|c|}{$\begin{array}{l}\text { 16. Abstract (Limit: } 200 \text { words) } \\
\text { This report describes the first year of a continuing research study to understand how recombinution, trapping, and band- } \\
\text { mobility modification affecting the electronic properties of amorphous semiconductors can be measured, characterized, and } \\
\text { described by an appropriate spectrum of defect states, and how light-induced defects in a-Si:H and native defects in a-SiGe:H } \\
\text { affect transport properties in these materials. The objective was to determine how the Staebler-Wronski defects affect the } \\
\text { electronic processes in a-Si:H and a-SiGe:H films. To do this, electroluminescence (EL) and forward bias current in p-i-n } \\
\text { devices (i-layer thickness }>2 \mu \mathrm{m} \text { ) were studied both experimentally and theoretically before and after light soaking. A } \\
\text { simple picture was developed to compare forward bias current to the EL signal. The result was unexpected: the product of } \\
\text { the final current times the rise time was not constant before and after light soaking as expected from the concept of gain band } \\
\text { width, but instead changed radically. The rise time t, increased by more than one order of magnitude while the final current } \mathrm{I}_{f} \\
\text { did not change significantly with light soaking. On the other hand, the } \mathrm{I}_{f} \text { product did hold close to a constant when only the } \\
\text { applied voltage changed. }\end{array}$} \\
\hline \multicolumn{4}{|l|}{$\begin{array}{l}\text { 17. Document Analysis } \\
\text { a. Descriptors } \\
\text { amorphous silicon; } \\
\text { b. Identiflers/Open-E } \\
\text { c. UC Categories } \\
271\end{array}$} \\
\hline \multirow{2}{*}{\multicolumn{3}{|c|}{$\begin{array}{l}\text { 18. Availabillty Statement } \\
\text { National Technical Information Service } \\
\text { U.S. Department of Commerce } \\
\text { 5285 Port Royal Road } \\
\text { Springfield, VA } 22161\end{array}$}} & $\begin{array}{l}\text { 19. No. of Pages } \\
20\end{array}$ \\
\hline & & & $\begin{array}{r}\text { 20. Price } \\
\mathrm{A03}\end{array}$ \\
\hline
\end{tabular}


$\nabla$
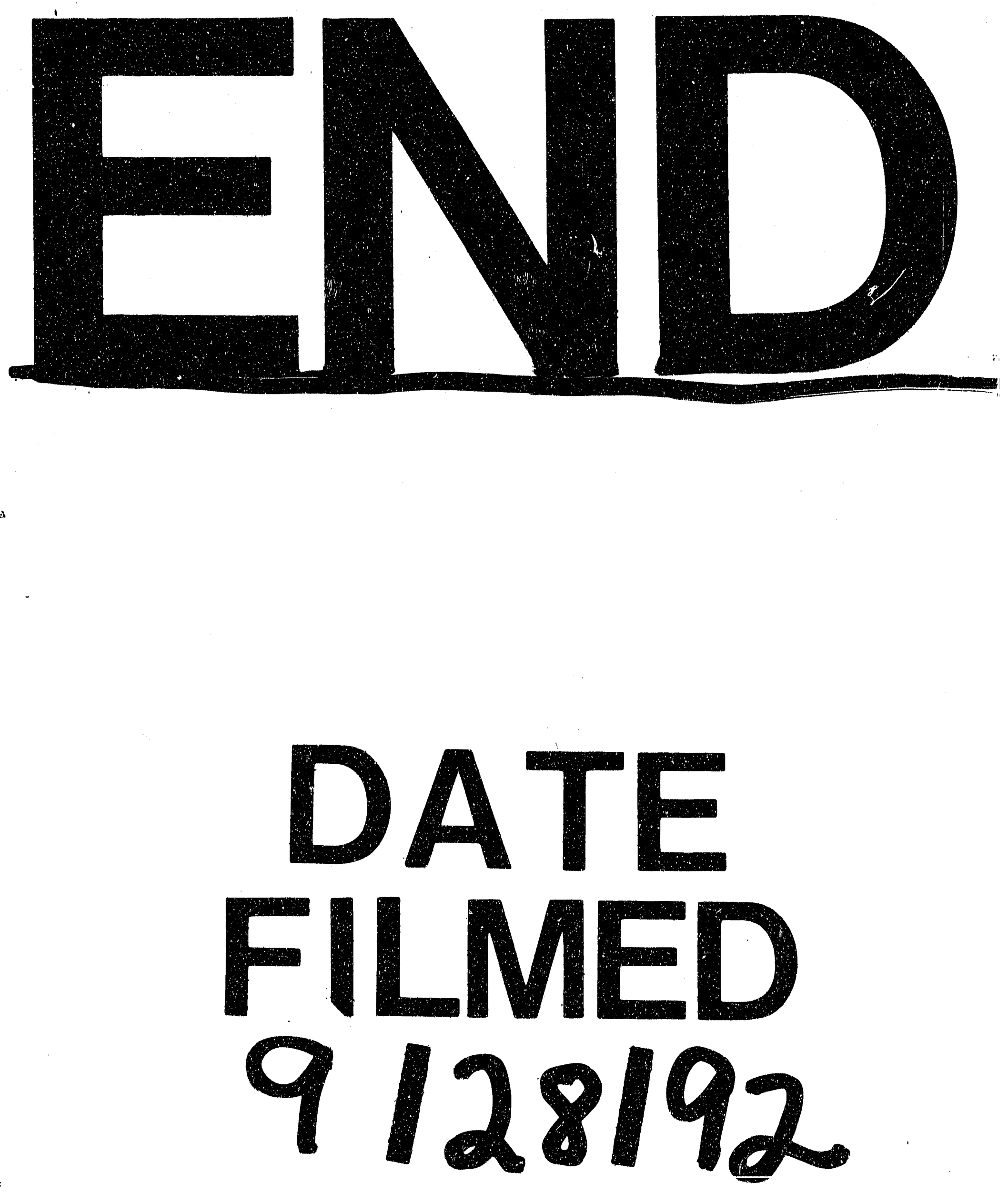
